\title{
Six months outcome of rescue percutaneous coronary intervention compared to conservative treatment in patients with ST-segment elevation myocardial infarction with failed fibrinolytic therapy
}

Mohamed Salem*, Mohamed Mahrous and Ahmed Ramzy

*Correspondence: masalem@yahoo.com

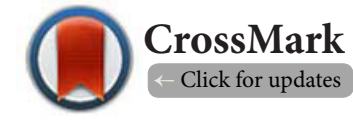

Department of Cardiology, Faculty of Medicine, Benha University, Egypt.

\begin{abstract}
Background: Fibrinolytic therapy restores patency of infarct related artery in about half of patients with STEMI. This study was designed to evaluate 6 months outcome after rescue PCI.

Methods: Sixty patients with STEMI were included in this controlled, prospective study. All patients had fibrinolytic therapy at baseline and had failed fibrinolysis detected by ECG and or persistence of chest pain. $50 \%$ of patients had rescue PCI and the others were treated conservatively. 30 days and 6 months major adverse cardiovascular events (MACE) were reported.

Results: After 30 days, angina required hospitalization was reported in $30 \%$ vs $7 \%$ in conservation and rescue groups $(\mathrm{P}=0.01)$. Target vessel revascularization was higher in conservative group $(13 \%)$ than rescue group $(0 \%),(\mathrm{P}=0.02)$. The 6 months follow up showed no motility benefit. However, re-hospitalization due to ACS and target vessel revascularization were more in the conservative group than rescue group, $40 \%$ vs $13 \%, 30 \%$ vs $1 \%$ respectively $(\mathrm{P}=0.02)$. Heart failure and re-infarction showed no significant difference between both groups. The mean LVEF vas higher in rescue PCI patients $(60 \pm 7 \%$ vs $45 \pm 8 \%)(\mathrm{P}=0.001)$.

Conclusion: Rescue PCI is safe, feasible and effective treatment option for patients with failed thrombolytic
\end{abstract} therapy.

Keywords: STEMI, fibrinolysis, rescue PCI, conservative treatment

\section{Introduction}

The benefits of an open infarct artery are well recognized, but despite proven advantage of primary percutaneous coronary intervention (PPCl), fibrinolysis remains the most common reperfusion strategy worldwide [1]. The future of patients with STEMI is dependent on the patency the culprit artery after reperfusion therapy [2]. Fibrinolysis is unable to restore normal coronary flow in $30-40 \%$ of treated patients [2]. The most appropriate treatment strategy for STEMI patients who have failed fibrinolytic therapy includes rescue $\mathrm{PCl}$, repeat fibrinolysis, or conservative treatment. ACC/AHA guidelines for STEMI recommend rescue $\mathrm{PCl}$ as class lla indication for patients who fail fibrinolytic therapy [1]. The lack of convincing data on how to treat STEMI patients who fail fibrinolytic therapy is reflected by the consistency in clinical practice where conservative therapy with no further reperfusion treatment, repeat fibrinolytic therapy, and rescue $\mathrm{PCl}$ are all being used commonly. The REACT (Rescue Angioplasty versus conservative treatment or repeat thrombolysis) trial demonstrated that rescue $\mathrm{PCl}$ is associated with an improvement in the composite end point of death, re-infarction, stroke and severe heart failure, when compared with repeat fibrinolytic therapy or conservative management [3]. However, this benefit was driven predominantly by a reduction in re-infarction, with no difference in survival between treatment strategies, moreover, this trial was terminated prematurely, before complete enrollment, raising concerns about the true estimate of benefits. A second contemporary study, the MERLIN (Middlesbrough Early Revascularization to Limit Infarction) trial did not show significant reduction of the primary end point of all-cause mortality as- 
Salem et al. Cardiovascular System 2015,

sociated with rescue $\mathrm{PCl}$ when compared with conservative therapy [4]. Furthermore, in both trials, patients treated with rescue $\mathrm{PCl}$ had increased bleeding, an important predictor of poor long-term outcome.

This study was designed to compare rescue $\mathrm{PCl}$ therapy versus conservative therapy in STEMI patients who have proven failed fibrinolysis to provide the best estimate of benefits and risks associated with these competing strategies.

\section{Patients and methods}

\section{Study design}

This prospective, controlled study included 60 patients with STEMI admitted to the coronary care unit (CCU) of cardiology department, Benha University Hospital, Benha, Egypt during the period from April 2009 to April 2011. We tested the safety and efficacy of rescue $\mathrm{PCl}$ compared to conservative treatment in patients who initially received fibrinolytic therapy but without clinical and or electrocardiographic evidence of successful reperfusion 90 minutes after start of fibrinolysis. All patients signed an informed consent and the study was approved by local ethics committee. Inclusion criteria were: Age: 30-80years, either sex, patients without absolute or relative contra-indications to fibrinolytic therapy, patients in whom fibrinolytic therapy failed to restore patency in infarct related artery clinically and or by ECG. While Exclusion Criteria were: inability to gain femoral access for intervention, life expectancy less than 6 months owing to non cardiac causes, cardiogenic shock, LBBB.

\section{Methods}

\section{Baseline evaluation}

a. Full history and clinical examination.

b. 12 lead ECG on admission and at 90,120 minutes after fibrinolysis and immediately after $\mathrm{PCl}$ in the rescue group and every 4 hours for 24 hours then once daily, and whenever indicated.

c. Routine laboratory investigations including, random blood sugar and lipid profile, kidney function tests (BUN and creatinine), liver function tests (PT, SGOT and SGPT), cardiac markers (CK-MB and Troponin) on admission and 6 hours later, hemoglobin level.

2. All patients were given fibrinolytic therapy (streptokinase), (1.5million units over 60 minutes).

3. Failure of fibrinolysis was defined as less than $50 \%$ regression in the ST segment elevation in the leads with maximum ST elevation and/or persistence or worsening of chest pain, 90 minutes after the start of fibrinolytic therapy.

4. Patients with fibrinolytic failure were subdivided into two groups:

Group I: Included 30 patients who underwent rescue PCI. Group II: Included 30 patients who were treated conservatively.

5. All patients received full anti-ischemic and anti-thrombotic drugs.

\section{Rescue PCI procedure}

The procedure was done according to the standard techniques of PCl. Femoral approach was the standard in all patients using 6 French sheaths. Diagnostic coronary angiography was done to detect the target vessel, X.B or JL guiding catheters were used for left coronary lesions and JR guiding catheter for RCA lesions. Aspiration devices and glycoprotein inhibitors were used in patients with heavy thrombus burden and impaired TMI flow grade after $\mathrm{PCl}$. Bare-metal stents were used in all patients. The operator determined the size and length of the stent. Rescue PCl was done for the culprit lesion only. The sheath was removed 6 hours from the end of the procedure and compression was done manually. Follow up of all patients was done during the hospital stay.

\section{Study end points}

Primary end point: 6 months adverse events including: All cause mortality, re-infarction, heart failure, target vessel revascularization (TVR).

Secondary end point: Left ventricular function at 6 months measured by echocardiography.

\section{Statistical analysis}

The collected data were tabulated and analyzed using SPSS version 17. Categorical variables were presented as number and percentages while continuous variables were expressed as mean \pm standard deviation. Chi square test (X2) "Z" test and student " $t$ " tests were used. The accepted level of significance in this work was stated $\mathrm{P}<0.05$.

\section{Results \\ Study population}

The mean age was $54 \pm 9$ years $(53 \pm 9.7$ years Vs $55 \pm 9$ years in rescue $\mathrm{PCl}$ group and conservative group respectively $\mathrm{P}=0.1$ ). Seventy eight percent (78\%) were males, $48 \%$ had diabetes mellitus, $38 \%$ were hypertensive. Smokers (either current or prior) were $62 \%$ of all patients, dyslipidemia was present in $67 \%$ of patients, $13 \%$ of patients had positive family history of IHD. No prior history of $\mathrm{PCl}, \mathrm{CABG}$, myocardial infarction or heart failure. There were no statistically significant differences between either group in demographic criteria, risk factors or past medical history (Table 1). However diabetes mellitus was more common in conservative patients, $63 \%$ compared to $33 \%, p=0.02$.

\section{Clinical presentation on admission}

Chest pain was the main clinical presenting symptom among the study group $(73 \%, 67 \%, 80 \%$, in all patients, rescue $\mathrm{PCl}$, conservative group respectively, $\mathrm{P}>0.05)$, dyspnea was the main presenting symptom in $13 \%$ of patients $(13 \%, 13 \%$, in rescue $\mathrm{PCl}$ and conservative group respectively, $\mathrm{P}>0.05$ ), pulmonary oedema was the main presenting symptom in 13\% of patients $(20 \%, 7 \%$, in rescue $\mathrm{PCl}$ and conservative group respectively, $\mathrm{P}=0.2$ ). 
Salem et al. Cardiovascular System 2015,

\section{Time from symptom onset to admission}

Most patients presented to CCU within 6 hours from symptom onset (92\%), $63 \%$ of patients in rescue PCI Vs $33 \%$ of those who were treated conservative presented within the first 3 hours ( $P=0.01)$, while $33 \%$ Vs $53 \%$ were admitted between 3-6 hours in $\mathrm{PCl}$ group and conservative group respectively $(\mathrm{P}=0.02)$, moreover $3 \%$ in $\mathrm{PCl}$ group Vs $13 \%$ in conservative group presented after 6 hours, $\mathrm{P}=0.03$. Table 2 .

Table 1. Baseline characteristics of study population.

\begin{tabular}{llll}
\hline & $\begin{array}{l}\text { Group I } \\
\text { Rescue PCI } \\
\mathbf{n = 3 0}\end{array}$ & $\begin{array}{l}\text { Group II } \\
\text { Conservative } \\
\mathbf{n = 3 0}\end{array}$ & P-value \\
\hline Age, years, mean \pm SD & $53.2 \pm 9.7$ & $54.8 \pm 9.1$ & 0.1 \\
Male gender, n (\%) & $23(77 \%)$ & $24(80 \%)$ & 0.2 \\
Diabetes M & $10(33 \%)$ & $19(63 \%)$ & 0.02 \\
Hypertension & $12(40 \%)$ & $11(36 \%)$ & 0.2 \\
Smoking & $18(60 \%)$ & $19(63 \%)$ & 0.3 \\
Dyslipidemia & $20(67 \%)$ & $20(67 \%)$ & -- \\
Family history of CAD & $4(13 \%)$ & $4(13 \%)$ & -- \\
Prior PCI or CABG & $0(0 \%)$ & $0(0 \%)$ & -- \\
Prior MI/CHF & $0(0 \%)$ & $0(0 \%)$ & -- \\
\hline
\end{tabular}

CAD: Coronary artery disease; PCI: Percutaneous coronary intervention; CABG: Coronary artery bypass grafting; MI: Myocardial infarction; CHF: Congestive heart failure

Table 2. Time from symptom onset to admission.

\begin{tabular}{llll}
\hline & Group I & Group II & P-value \\
\hline Within 3 hours, n(\%) & $19(63 \%)$ & $10(33 \%)$ & 0.01 \\
Between 3 to 6 hours & $10(33 \%)$ & $16(53 \%)$ & 0.02 \\
$>$ 6 hours & $1(3 \%)$ & $4(13 \%)$ & 0.03 \\
\hline
\end{tabular}

\section{Clinical examination on admission}

There was no statistically significant difference between the study groups considering heart rate and systolic blood pressure at presentation (the mean systolic blood pressure was $136 \pm 25 \mathrm{mmHg}$ in group I \& $125 \mathrm{mmHg} \pm 29$ in group II, while the mean heart rate was $85.7 \pm 14.5$ in group $1 \& 79.4 \pm 16$ in group II, $\mathrm{P}=0.1$ ). Killip II \& III presentation was more in group I ( $47 \% \& 20 \%$ versus $33 \% \& 7 \%, P=0.2)$.

\section{Target segment of STEMI according to ECG}

Anterior Ml was the most common type of infarction (45\% of patients), $63 \%$ in group I Vs. $27 \%$ in group II ( $P=0.01)$. Anterolateral infarction was present in $30 \%$ of patients, $(27 \%$ in group IVs. $34 \%$ in group II, $\mathrm{P}=0.5)$. Anteroseptal infarction was evident in $3 \%$ of patients $(0 \% \mathrm{Vs} .7 \%$ in group I and II respectively, $\mathrm{P}=0.4$ ). Inferior infarction occurred in one patient only of the study (in group I), while inferior and right ventricular and or posterior infarction was detected in $20 \%$ of all patients ( $7 \%$ and $33 \%$ in group I and II respectively, $\mathrm{P}=0.01$ ), (Figure 1).

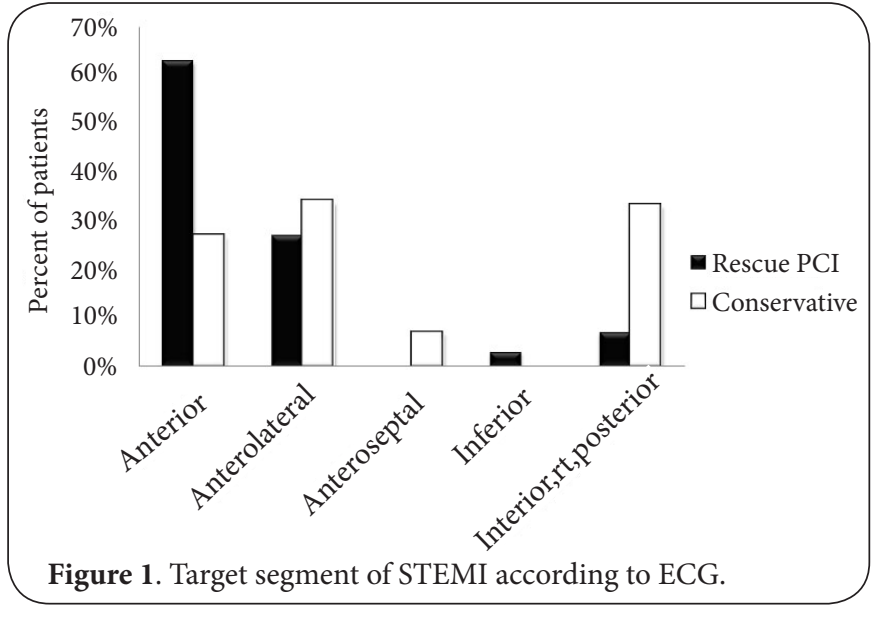

\section{Rescue PCI}

The mean time from diagnosis of failed reperfusion till the start of sheath insertion in the cath lab was $3.0 \pm 1.2$ hours (range 1.5 to 6 hours), two patients (6.7\%) had time of less than 2 hours, 17 patients (57\%) had time between 2-3 hours, while 11 patients $(37 \%)$ had time between $3-6$ hours. All patients received $10.000 \mathrm{U}$ of UFH pre $\mathrm{PCl}$. Transfemoral approach was done in all patients. The target artery was LAD in $90 \%$ of cases, RCA in $10 \%$ of cases. Among the LAD patients, the occlusion was in proximal segment in $85 \%$, in mid segment in $15 \%$. In RCA patients $100 \%$ cases had proximal occlusion. TIMI flow 0 was detected in $47 \%$ of patients, TIMI 1 in $47 \%$, and TIMI II flow in $7 \%$ of patients. XB guiding catheter was used in all patients who had LAD as the target artery. While JR catheter was used in those who had RCA as the target artery. Floppy wire was used in $43 \%$ of cases, while coated wire was used in 57\%. Predilatation was done in all cases either due to shortage of aspiration devices or presence of critical lesion after thrombus aspiration. Intracoronary glycoprotein inhibitors were injected in $43 \%$ of cases, this was followed by intravenous infusion for an average time 12 hours in $10 \%$ of patients, manual aspiration devices were used in 9 patients (30\%). Large thrombus burden or impaired TIMI flow were the main indications. Implantation of Bare-metal stent (BMS) was performed in 27 patients (90\%). Twenty three patients had 1 stent while four patients had 2 stents. The mean stent diameter was $3.2 \pm 0.8 \mathrm{~mm}$, the mean stent length was $15 \pm 3.3 \mathrm{~mm}$. The mean implantation pressure was $13.5 \pm 1$ ATM. Post dilatation was done in $17 \%$ of patients due to residual stenosis. TIMI flow at the end of rescue $\mathrm{PCl}$ was III in $90 \%$ of patients and II in $10 \%$ of patients. Distal embolization occurred in $13 \%$ of patients, No reflow in $13 \%$ of patients.

\section{In hospital outcome}

No mortality was reported in either group, also no reported cases of re-infarction, heart failure, stroke, recurrent ischemia, need for urgent intervention, arrhythmia, or major bleeding during the hospital stay, but minor bleeding in $18 \%$ of patients, 
Salem et al. Cardiovascular System 2015,

http://www.hoajonline.com/journals/pdf/2052-4358-3-4.pdf

doi: $10.7243 / 2052-4358-3-4$

$30 \%, 7 \%$ in rescue $\mathrm{PCl}$ and conservative group respectively $(\mathrm{P}=0.01)$.

\section{Thirty days outcome}

Major adverse events were reported in $50 \%$ of patients who were treated conservatively compared to $20 \%$ of patients treated with rescue $\mathrm{PCl}(\mathrm{p}=0.02)$. Angina requiring hospitalization was reported in $18 \%$ of patients, $30 \%$ in the conservative group compared to $7 \%$ in rescue $\mathrm{PCl}$ group $(\mathrm{P}=0.01)$. Target vessel revascularization was performed in $13 \%$ of conservative group II Vs $0 \%$ in rescue $\mathrm{PCl}$ group I $(\mathrm{P}=0.02)$. Development of heart failure occurred in $30 \%$ of conservative patients compared to $20 \%$ in rescue $\mathrm{PCl}$ patients $(\mathrm{P}=0.3)$. Re-infarction was reported in one patient (group II). No mortality, or major bleeding, but minor bleeding occurred in $30 \%$ and $7 \%$ in $\mathrm{PCl}$ and conservative group respectively $(\mathrm{P}=0.01)$. There was a trend for positive correlation between time to cath lab and occurrence of heart failure and angina requiring re hospitalization with less frequency in those who had shorter time. Thirty days mean LVEF in group I was higher than group II, 50 $\pm 8 \%$ Vs. $48 \% \pm 9 \%$ but was not statistically significant $(P=0.5)$.

\section{Six months outcome}

No reported cases of mortality. Re-hospitalization due to unstable angina was reported in $40 \%$ of patient in group II Vs $13 \%$ in group I. ( $P=0.02)$. Heart failure occurred in $20 \%$ Vs $10 \%$ in conservation $V s$ rescue group $P=0.3$. Target vessel revascularization was more in the conservative group than rescue group $20 \%$ Vs $1 \%$ respectively $(P=0.001)$. The mean LVEF was significantly higher in group I than group II, $60 \pm 7 \%$ Vs $45 \pm 8 \%(\mathrm{P}=0.001)$.

\section{Discussion}

Despite potential advantages of primary percutaneous coronary intervention (PPCl), fibrinolytic therapy remains the most common therapy for STEMI worldwide [5]. Practical guidelines for STEMI recommend rescue $\mathrm{PCl}$ as a class lla indication in the treatment of patients with STEMI who had failed fibrinolytic therapy [6]. This controlled study evaluated the safety \& efficacy of rescue $\mathrm{PCl}$ as an optional treatment in patients with STEMI who received fibrinolytic therapy but without evidence of successful reperfusion. We reported a better 6 months outcome with rescue $\mathrm{PCl}$ with lower re-hospitalization due to ACS, heart failure and better LVEF.

In our study the mean age was 54 years \& the female patients represented $22 \%$ of the study population. In RESCUE trial the mean age was 59 years and female subjects represented $18 \%$ of the study population.

Most of patients in the present study (92\%) had time from symptom onset within 6 hours. In REACT, MERLIN, and RESCUE trials the time from symptom onset to fibrinolytic therapy was $2,3,3$ hours respectively. The difference between our results and these trials is related to the diagnosis, education of the patients, and long transport time.
Time from symptom onset was shorter in rescue $\mathrm{PCl}$ patients. However this was not translated into better end points like mortality heart failure.

Anterior wall myocardial infarction was reported in (78\%) of patients. In the REACT trial, anterior STEMI represented $43 \%$ of the study population. In another study which included 90 patients, anterior wall MI represented $56 \%$ of patients [7]. This difference may be related to small size and difference of the study population. The time from diagnosis of failure of fibrinolysis until the start of intervention was $3.1 \pm 1.2$ hours. In MERLIN trial, the mean time from 60 minutes ECG (diagnosis of failure) to coronary angiography was $1.5 \pm 0.5$ hour. While Ellis et al., 1994 [8] reported that the mean time from presentation to angiography was $4.5 \pm 2$ hours. In REACT trial the mean time from 90 minutes ECG to rescue $\mathrm{PCl}$ was $5 \pm 3$ hours. Rescue $\mathrm{PCl}$ is defined as $\mathrm{PCl}$ within $12 \mathrm{~h}$ after failed fibrinolysis for patients with continuing or recurrent myocardial ischemia [9]. A major limitation in adapting a strategy of rescue $\mathrm{PCl}$ is the difficulty in identifying patients for whom fibrinolytic therapy has not restored ante grade coronary flow [9]. Unless unsuccessful fibrinolysis is recognized and treated quickly (within 3-6 hours of onset of symptoms), salvage of ischemic myocardium is unlikely.

LAD was the main target vessel in the rescue group \& represented $90 \%$, while RCA was the target vessel in $10 \%$. In the RESCUE trial all patients had LAD occlusion as target for infarction. However in the MERLIN trial it represented only $44 \%$, in addition in REAT trial it represented only $43 \%$ of patients. Most of our patients (73\%) had single vessel disease; to our knowledge this point in other trials is not known. Intra coronary glycoprotein inhibitors were used in $43 \%$ of rescue $\mathrm{PCl}$ patients. In MERLIN trial only 5 patients (3\%) received glycoprotein inhibitors [4]. In the study done by Burjonroppa et al [10], 59\% of patients received glycoprotein inhibitors and $43 \%$ of patients in the REACT trial received this medication. Aspiration devices were used in 9 patients (30\%) mainly due to shortage of these devices in our lab $90 \%$ of patients of the rescue group in our study had TIMI 3 flow post $\mathrm{PCl}$. These results are in agreement with the results of the MERLIN trial (85\%) of patients had TIMI 3 flow post PCI [4].

In the present study there were no reported cases of major bleeding. In REACT trial, the incidence of major bleeding was $2.7 \%$ in the rescue $\mathrm{PCl}$ group and $3.6 \%$ in the conservative group.

At 6 months, angina requiring hospitalization was reported in $13 \%$ in the rescue $\mathrm{PCl}$ group compared to $40 \%$ in the conservative group. In addition TVR was done in $20 \%$ of patients in the conservative group versus $3 \%$ in $\mathrm{PCl}$ group. These results are concordant with the results of the MERILN trial [4] in which $6.5 \%$ versus $20.1 \%$ had TVR in rescue $\mathrm{PCl}$ and conservative group respectively. Congestive heart failure in the present study occurred in $20 \%$ in the conservative therapy group compared to $10 \%$ in the rescue $\mathrm{PCl}$ group. The metaanalysis done by Wijeysundera et al., [11] which included six 
Salem et al. Cardiovascular System 2015,

trials (including REACT, MERLIN and RESCUE trials) reported significant reduction in the relative risk ( $\mathrm{RR} 0.73,956 \% \mathrm{Cl} 0.54$ 10.00) of heart failure in the rescue $\mathrm{PCl}$ group after follow up period six months.

\section{Study limitation}

Small sample size.

Lake of randomization.

\section{Conclusion}

Rescue PCl improved clinical outcome compared to conservative approach in patients with STEMI who have failed fibrinolytic therapy.

\section{List of abbreviations}

STEMI: St Segment Elevation Myocardial Infarction

PCI: Percutaneous Coronary Intervention

MACE: Major Adverse Cardiovascular Events

CAD: Coronary Artery Disease

\section{Competing interests}

The authors declare that they have no competing interests.

\section{Authors' contributions}

\begin{tabular}{|l|c|c|c|}
\hline Authors' contributions & MS & MM & AR \\
\hline Research concept and design & $\checkmark$ & $\checkmark$ & $\checkmark$ \\
\hline Collection and/or assembly of data & $\checkmark$ & $\checkmark$ & $\checkmark$ \\
\hline Data analysis and interpretation & $\checkmark$ & $\checkmark$ & $\checkmark$ \\
\hline Writing the article & $\checkmark$ & $\checkmark$ & $\checkmark$ \\
\hline Critical revision of the article & $\checkmark$ & $\checkmark$ & $\checkmark$ \\
\hline Final approval of article & $\checkmark$ & $\checkmark$ & $\checkmark$ \\
\hline Statistical analysis & $\checkmark$ & $\checkmark$ & $\checkmark$ \\
\hline
\end{tabular}

Publication history

Editor: Harvey R. Weiss, Robert Wood Johnson Medical School, USA. Received: 28-Oct-2015 Final Revised: 30-Nov-2015

Accepted: 09-Dec-2015 Published: 16-Dec-2015

\section{References}

1. Antman EM, Anbe DT, Armstrong PW, Eric RB,; Lee AG, Mary H, Judith S, Harlan M and Frederick GK. ACC/AHA guide lines for the management of patients with ST-elevation myocardial infarction; a report of the American College of Cardiology/American Heart Association Task Force on Practice Guidelines (Committee to Revise the 1999 Guidelines for the Management of Patients with Acute Myocardial Infarction). J Am Coll Cardiol. 2004; 44:671-719. | Article

2. Keeley EC, Boura JA and Grines CL. Primary angioplasty versus intravenous thrombolytic therapy for acute myocardial infarction: a quantitative review of 23 randomised trials. Lancet. 2003; 361:13-20. | Article | PubMed Abstract | PubMed Full Text

3. Gershlick AH, Stephens-Lloyd A, Hughes S, Abrams KR, Stevens SE, Uren NG, de Belder A, Davis J, Pitt M and Banning A et al. Rescue angioplasty after failed thrombolytic therapy for acute myocardial infarction. $N$ Engl J Med. 2005; 353:2758-68. | Article | PubMed

4. Sutton AG, Campbell PG, Graham R, Price DJ, Gray JC, Grech ED, Hall JA, Harcombe AA, Wright RA, Smith RH, Murphy JJ, Shyam-Sundar A, Stewart MJ, Davies A, Linker NJ and de Belder MA. A randomized trial of rescue angioplasty versus a conservative approach for failed fibrinolysis in ST-segment elevation myocardial infarction: the Middlesbrough Early Revascularization to Limit INfarction (MERLIN) trial. J Am Coll Cardiol. 2004; 44:287-96. | Article | PubMed
5. Eagle KA, Goodman SG, Avezum A, Budaj A, Sullivan CM and LopezSendon J. Practice variation and missed opportunities for reperfusion in ST-segment-elevation myocardial infarction: findings from the Global Registry of Acute Coronary Events (GRACE). Lancet. 2002; 359:373-7. I Article I PubMed

6. Van de Werf F, Ardissino D, Betriu A, Cokkinos DV, Falk E, Fox KA, Julian D, Lengyel M, Neumann FJ, Ruzyllo W, Thygesen C, Underwood SR, Vahanian $A$, Verheugt FW and Wijns W. Management of acute myocardial infarction in patients presenting with ST-segment elevation. The Task Force on the Management of Acute Myocardial Infarction of the European Society of Cardiology. Eur Heart J. 2003; 24:28-66. | Article | PubMed

7. Sarullo FM, Americo L, Di Pasquale P, Castello A and Mauri F. Efficacy of rescue thrombolysis in patients with acute myocardial infarction: preliminary findings. Cardiovasc Drugs Ther. 2000; 14:83-9. | Article | PubMed

8. Ellis SG, da Silva ER, Heyndrickx G, Talley JD, Cernigliaro C, Steg G, Spaulding C, Nobuyoshi M, Erbel R, Vassanelli C and et al. Randomized comparison of rescue angioplasty with conservative management of patients with early failure of thrombolysis for acute anterior myocardial infarction. Circulation. 1994; 90:2280-4. | Article | PubMed

9. Antman EM, Anbe DT, Armstrong PW, Bates ER, Green LA, Hand M and Hochman JS. ACC/AHA guidelines for the management of patients with ST-elevation myocardial infraction; a report of the American College of Cardiology/American Heart Association Task Force on Practice Guidelines (Committee to Revise the 1999 Guidelines for the Management of Patients with Acute Myocardial Infarction). J Am Coll Cardiol. 2004; 44:671-719. | Article

10. Burjonroppa Sukesh C, Paul D, Varosy, Ou FS, Roe M, Peterson E, Singh $M$ and Shunk KA. Survival of patients undergoing rescue percutareous coronary intervention. J Am Coll cardiol. 2010; 40:42-50.

11. Wijeysundera HC, Vijayaraghavan R, Nallamothu BK, Foody JM, Krumholz HM, Phillips CO, Kashani A, You JJ, Tu JV and Ko DT. Rescue angioplasty or repeat fibrinolysis after failed fibrinolytic therapy for ST-segment myocardial infarction: a meta-analysis of randomized trials. J Am Coll Cardiol. 2007; 49:422-30. | Article | PubMed Abstract | PubMed Full Text

\section{Citation:}

Salem M, Mahrous M and Ramzy A. Six months outcome of rescue percutaneous coronary intervention compared to conservative treatment in patients with ST-segment elevation myocardial infarction with failed fibrinolytic therapy. Cardio Vasc Syst. 2015; 3:4.

http://dx.doi.org/10.7243/2052-4358-3-4 